\title{
Cold Plasma Generation of Peracetic Acid for Antimicrobial Applications
}

\author{
Bhagirath Ghimire, ${ }^{a, *}$ Endre J. Szili, ${ }^{b}$ Bethany Lee Patenall, ${ }^{c}$ Adrian Fellows, ${ }^{d}$ \\ Dharmit Mistry, ${ }^{d}$ Andrew Toby A. Jenkins, ${ }^{c}$ \& Robert D. Short ${ }^{a, b}$ \\ aDepartment of Chemistry, Lancaster University, Lancaster LA1 4YB United Kingdom; ' Future \\ Industries Institute, University of South Australia, Adelaide SA 5095, Australia; 'Department of \\ Chemistry, University of Bath, Bath BA2 7AY United Kingdom; 'AGA Nanotech Ltd., 2 Regal \\ Way, Watford, Hertfordshire WD24 4YJ United Kingdom
}

*Address all correspondence to: Bhagirath Ghimire, Department of Chemistry, Lancaster University, Lancaster LA1 4YB United Kingdom, E-mail: ghimirebhagi@hotmail.com; r.d.short1@lancaster.ac.uk

\begin{abstract}
This study compares how a helium plasma jet activates peracetic acid (PAA) from tetraacetylethylenediamine (TAED) and acetic acid (AA). Hydrogen peroxide $\left(\mathrm{H}_{2} \mathrm{O}_{2}\right)$ generated from the plasma jets reacts with TAED resulting in the formation of PAA which further dissociates into AA. The by-product AA can also react with $\mathrm{H}_{2} \mathrm{O}_{2}$ to form PAA, which might also be useful for antimicrobial applications when coupled with plasma. Equivalent concentrations of TAED and AA solutions are used to compare the formation of PAA after activation with a helium plasma jet. Our results showed that the concentrations of both $\mathrm{H}_{2} \mathrm{O}_{2}$ and PAA in plasma-activated TAED (PAT) are higher than plasma-activated AA (PAAA), and that PAT is more efficient in reducing the growth of Pseudomonas aeruginosa and Staphylococcus aureus; the pathogens commonly found in wounds. The results are attributed to the presence of more acetyl donor groups in TAED, resulting in the formation of higher concentrations of PAA and $\mathrm{H}_{2} \mathrm{O}_{2}$.
\end{abstract}

\section{INTRODUCTION}

Plasma-activated water (PAW) has been shown to be an effective antibacterial solution against a range of bacteria for medical and food related decontamination applications. ${ }^{1-3}$ Even though the chemistry of PAW can be varied in a number of ways, its main antimicrobial effects are usually mainly attributed to the combination of hydrogen peroxide $\left(\mathrm{H}_{2} \mathrm{O}_{2}\right)$ and nitrogen oxide species that reduce the $\mathrm{pH}$ of water. ${ }^{4-7}$ The reason for this is that most plasma treatments produce a much higher concentration of $\mathrm{H}_{2} \mathrm{O}_{2}$ compared to other generated reactive species, and they also produce peroxynitrous acid that decreases the water's $\mathrm{pH}$. Acidification is known to enhance the antibacterial property of $\mathrm{H}_{2} \mathrm{O}_{2} \cdot{ }^{1-5}$

The use of PAW as an antibacterial agent has been investigated across several industries, including medicine, ${ }^{2,8,9}$ agriculture, ${ }^{10,11}$ and food. ${ }^{3}$ PAW has been shown to have a high level of antibacterial efficacy in the above applications, including against antibiotic-resistant bacteria. ${ }^{12-14}$ These results have raised enthusiasm that PAW can potentially offer an antibiotic-free solution to combat the rise of antimicrobial resistance (AMR) in healthcare and in our environment. However, given that the use of PAW as an antimicrobial agent is still relatively new and for many applications is is still at the research phase and has not seen widespread industry use, it is still unknown how the 
longer-term exposure of PAW to microorganisms might also result in facilitating AMR. Early work suggests that bacteria are indeed able to develop resistance against plasma treatments. ${ }^{15}$ The main hypothesis in these studies is that bacteria release catalase in response to oxidative stress produced by the plasma treatment. ${ }^{16}$ Catalase neutralizes $\mathrm{H}_{2} \mathrm{O}_{2}$, which can prevent oxidative damage to the host bacterial cell.

To overcome the bacteria's oxidative defense mechanisms, we have developed a new PAW formulation by adding the antimicrobial precursor acetyl donor molecules tetraacetylethylenediamine (TAED) and pentaacetate glucose (PAG) ${ }^{17}$ into the water (prior to plasma treatment). Plasma-generated $\mathrm{H}_{2} \mathrm{O}_{2}$ activates the acetyl donor molecules, generating a potent oxidant, peracetic acid (PAA), that acts in synergy with $\mathrm{H}_{2} \mathrm{O}_{2}$ and other reactive oxygen and nitrogen species (RONS) generated by plasma in the water [Reaction (1) in Fig. 1]. ${ }^{18}$ Also, Fig. 1 shows the acetyl donor groups $\mathrm{CH}_{3} \mathrm{CO}$ on TAED and on the by-product AA of the TAED- $\mathrm{H}_{2} \mathrm{O}_{2}$ reaction. PAW in combination with plasma-activated acetyl donors was shown to be superior in the decontamination of Gram-negative and Gram-positive bacteria as well as the SARS-CoV-2 virus compared to the use of PAW alone. ${ }^{17}$

This present study aims to provide further insights into the chemistry of the plasmaactivated acetyl donor reaction to better understand the importance of the processing parameters in PAA generation. Specific focus is given to the plasma activation of TAED compared to acetic acid (AA). As shown in Fig. 1, Reactions (2) and (3), AA is a byproduct produced by the reaction of an acetyl donor with $\mathrm{H}_{2} \mathrm{O}_{2}$. Because AA also contains an acetyl group, it can subsequently react with $\mathrm{H}_{2} \mathrm{O}_{2}$ to form PAA through a reversible reaction [Fig. 1, Reaction (2)]. Therefore, by carrying out this study we can determine if other agents such as AA can be used instead of commonly used acetyl donors such as TAED, as well as provide new information on the chemical pathways involved in the enhancement of the antibacterial activity of PAW with PAA.

\section{METHODS AND MATERIALS}

\section{A. Plasma Jet Setup}

Figure 2 is a schematic of the experimental setup with a photograph of the plasma jet. The plasma jet assembly consists of a 150-mm-long, 3-mm-inner-diameter glass tube tapered to

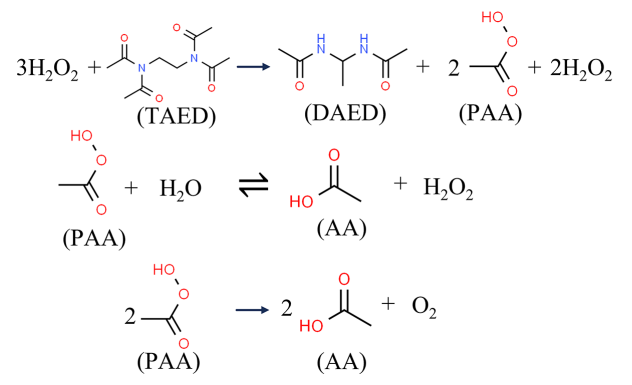

FIG. 1: Formation of PAA through the reaction of TAED or AA with plasma-produced $\mathrm{H}_{2} \mathrm{O}_{2}$ 


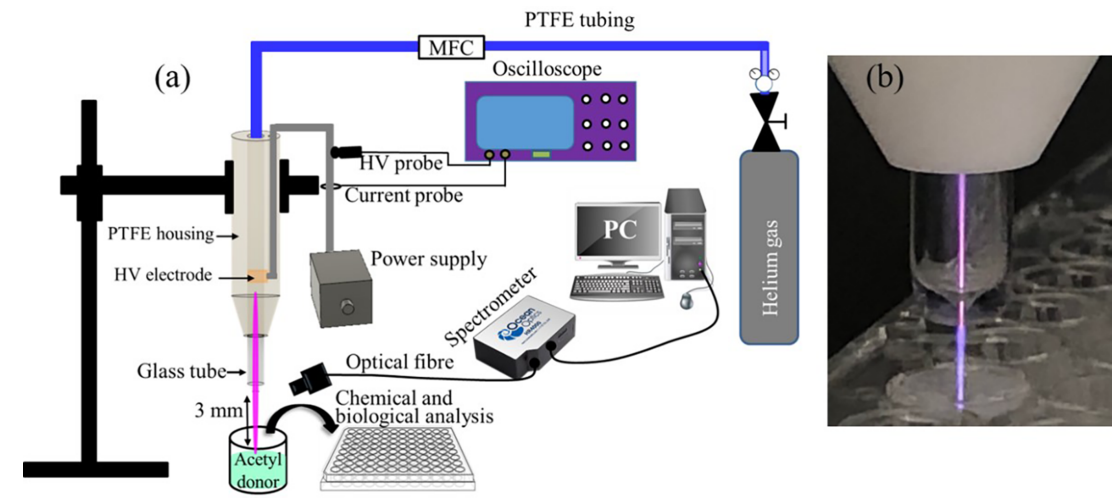

FIG. 2: (a) Schematic of experimental setup; (b) He plasma jet treating an acetyl donor solution

$600 \mu \mathrm{m}$ at the nozzle. A single 15-mm-long external ring copper electrode is wound onto the glass tube $50 \mathrm{~mm}$ above the nozzle. The flow rate of helium $(\mathrm{He})$ through the glass tube is fixed at 1 standard liter per minute (SLPM). Plasma is generated by supplying a high voltage of $10 \mathrm{kV} \mathrm{p}$-p (peak-peak) at $25 \mathrm{kHz}$ to the copper electrode using a commercial power supply (PVM500, Information Unlimited, USA). Voltage and current waveforms are measured using a high-voltage probe (Pingtek Electronics, Taipei, Taiwan) and a current monitor (Pearson Electronics, Palo Alto, CA, USA), respectively, with the waveforms recorded on an oscilloscope (Sigilent Technologies, Solon, OH, USA). The optical emission signals of the discharge are measured with a spectrometer (Ocean Optics HR4000 CG-UV-NIR).

\section{B. Preparation and Analysis of Antimicrobial Solutions}

Antimicrobial solutions used to compare the formation of PAA with the plasma jet consisted of (1) 5 mM TAED (CAS No. 10543-57-4, Sigma Aldrich, St. Louis, MO, USA), (2) 5 mM AA (CAS No. 64-19-7, Sigma Aldrich), and (3) deionized water (DIW; resistivity $18.2 \mathrm{M} \Omega \mathrm{cm}$ ). A $400-\mu \mathrm{L}$ volume of TAED, AA, or DIW was transferred to a well of a 96-well plate (Corning Inc., Corning, NY, USA) and treated with the plasma jet for $20 \mathrm{~min}$. The distance between the plasma jet nozzle and the top of the DIW surface was $3 \mathrm{~mm}$. Analysis of the characteristics of the antimicrobial solutions was performed using the three techniques described next.

\section{Measurement of $\mathrm{H}_{2} \mathrm{O}_{2}$ Concentration}

Measurement of $\mathrm{H}_{2} \mathrm{O}_{2}$ concentration was carried out using a reaction to assess the horseradish peroxidase (HRP; CAS No. 9003-99-0, SigmaAldrich) catalyzed oxidation of o-phenylenediamine (OPD CAS No. 95-54-5, SigmaAldrich) as previously described. ${ }^{17}$ $\mathrm{HRP}$ catalyzes the oxidation of OPD with $\mathrm{H}_{2} \mathrm{O}_{2}$, which forms a final yellow product, 2-3-diaminophenazine with an absorbance maximum at $450 \mathrm{~nm}$. A tablet of OPD was dissolved in $10 \mathrm{~mL}$ DIW, and $20 \mu \mathrm{L}$ of $2-\mathrm{mg} / \mathrm{mL}$ HRP was added to the solution. $20 \mu \mathrm{L}$ 
antimicrobial solution (or $\mathrm{H}_{2} \mathrm{O}_{2}$; CAS No. 7722-84-1, Sigma Aldrich) was added to the wells of a 96-well plate containing $180 \mu \mathrm{L}$ dissolved OPD-HRP, and incubated for 15 min at ambient temperature in the dark. The absorbance at $\lambda=450 \mathrm{~nm}$ of the solutions was measured on a microplate reader (Synergy LX, Biotek). The absorbance measurements directly correlated with the $\mathrm{H}_{2} \mathrm{O}_{2}$ concentration, which was subsequently calculated from a line-of-best-fit calibration curve (Fig. A1 in Appendix A).

\section{Measurement of PAA}

The PAA concentration in the plasma-activated solutions was measured using the following reagents: (1) potassium iodide (KI; CAS No. 7681-11-0, Sigma Aldrich), (b) catalase (CAS No. 9001-05-02, Sigma Aldrich), and (3) PAA (Fisher Scientific, Hampton, NH, USA). Then $20 \mu \mathrm{L}$ of $100-\mathrm{mg} / \mathrm{mL}$ catalase was mixed with $5 \mu \mathrm{L}$ known concentrations of PAA (or plasma-activated solutions) and incubated for $15 \mathrm{~min}$. Any $\mathrm{H}_{2} \mathrm{O}_{2}$ present in the antimicrobial solution was quenched by the catalase, resulting in the oxidation of KI mainly from PAA due to its significantly higher oxidative capacity compared to the remaining plasma-produced oxidative species. ${ }^{17}$ Finally, the oxidation of KI was measured by adding $5 \mu \mathrm{L}$ test solution in $195 \mu \mathrm{L}$ of $100-\mathrm{mM} \mathrm{KI}$ and incubated for $15 \mathrm{~min}$. The absorbance of the resulting solution was measured at 350 nm using a plate reader (Synergy LX, Biotek). The calibration curve constructed with known concentrations of PAA (Fig. A2 in Appendix A) was then used to measure the concentration of PAA formed in PAT or PAAA.

\section{3. $\mathrm{H}_{2} \mathrm{O}_{2}$ Activation of TAED and AA}

This experiment was conducted in order to compare the oxidation efficiency of TAED and AA following reactions with different concentrations of $\mathrm{H}_{2} \mathrm{O}_{2}$. To begin, $20 \mu \mathrm{L}$ of different concentrations of $\mathrm{H}_{2} \mathrm{O}_{2}$ were added into $180 \mu \mathrm{L}$ of $100-\mathrm{mM} \mathrm{KI}$ and incubated at room temperature for $15 \mathrm{~min}$. Afterwards, the absorbance was read at $350 \mathrm{~nm}$ using a plate reader (Biotek, Winooski, VT, USA).

\section{Antimicrobial Assays}

Common wound pathogens Pseudomonas aeruginosa (P. Aeruginosa, PA01) and Staphylococcus aureus (S. Aureus, H560) were used for studying the bactericidal effect of plasma-activated TAED and AA solutions. A $400 \mu \mathrm{L}$ solution of 5-mM TAED in DIW, $5 \mathrm{mM}$ AA in DIW, and DIW alone were treated with the He plasma jet for $20 \mathrm{~min}$ in a 96-well plate (frequency: $20 \mathrm{kHz}$, He gas flow: $1 \mathrm{LPM}$, applied voltage: $10 \mathrm{kV} \mathrm{p}$-p). After treatment, $80 \mu \mathrm{L}$ of the plasma-activated solution was transferred to another well containing $80 \mu \mathrm{L}$ of the bacteria (initial concentration $=10^{6} \mathrm{CFU} / \mathrm{mL}$ ). The bacterial culture mixed with the plasma-activated solution was incubated for $12 \mathrm{~h}$. The optical density of the solution at $\lambda=600 \mathrm{~nm}\left(\mathrm{OD}_{600}\right)$ was used to determine the comparative growth of the bacteria in the various samples. 


\section{RESULTS AND DISCUSSION}

\section{A. Electrical and Optical Characteristics}

The electrical and optical characteristics of the He plasma jet used to produce the plasmaactivated solutions are shown in Fig. 3. Plasma was generated at 1-SLPM He flow by applying a sinusoidal voltage of $10 \mathrm{kV}$ p-p at a frequency of $25 \mathrm{kHz}$. Typical current (I) and voltage $(\mathrm{V})$ waveforms of the He plasma jet during treatment of the DIW are shown in Fig. 3(a). Accumulation of wall charges took place on the inner side of the quartz tube during the rising time of the applied voltage. These wall charges gave rise to a current peak. During the falling time, these charges were reversed in the voltage polarity, which gave rise to the current peak in the negative direction. ${ }^{4,19,20}$ The root mean-square (RMS) value of the current was calculated to be $5.91 \mathrm{~mA}$. The I-V waveforms were used to calculate the dissipated power $(\mathrm{P}) \mathrm{as}^{5}$

$$
P=\frac{1}{T} \int_{t=0}^{t=T} I(t) V(t) \mathrm{d} t
$$
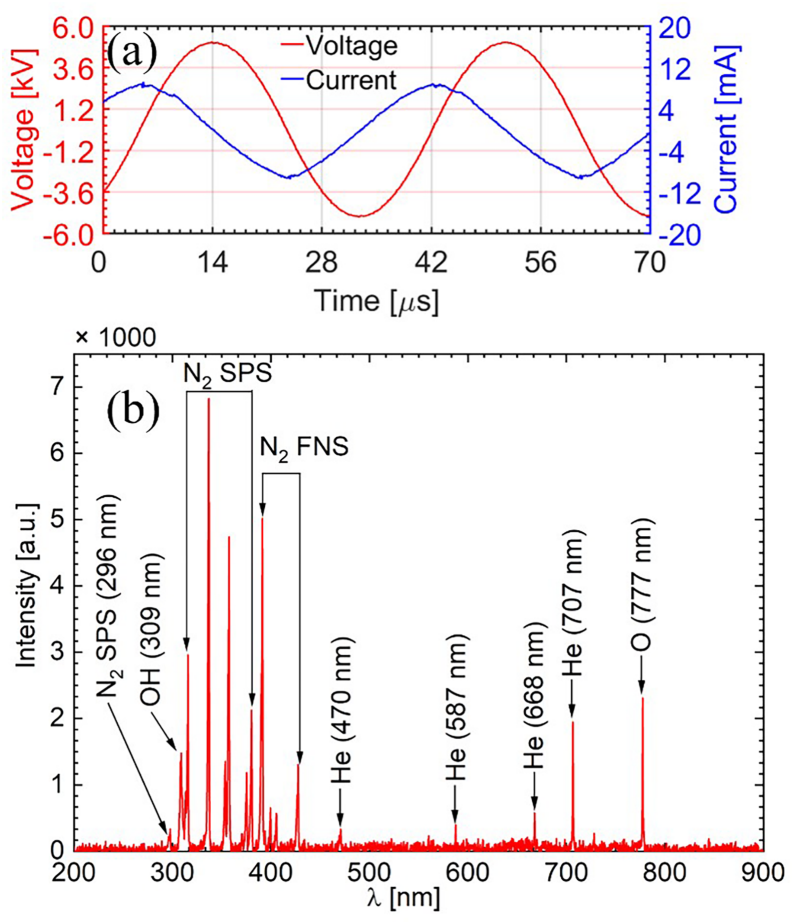

FIG. 3: (a) Typical current and voltage waveforms of the He plasma jet during treatment of DIW; and (b) typical optical emission spectrum of the free stream He plasma jet measured at $3 \mathrm{~mm}$ below the plasma jet nozzle

Volume 11, Issue 4, 2021 
Ghimire et al.

where $I(t)$ and $V(t)$ represent the instantaneous values of current and voltage, respectively, at a time $t$ within a period $T$. The total dissipated power was calculated to be 0.6 W.

A typical optical emission spectrum of the He plasma jet recorded between 200$900 \mathrm{~nm}$ is shown in Fig. 3(b). The spectrum was measured for a free stream plasma jet at $3 \mathrm{~mm}$ below the plasma jet nozzle at an integration time of $70 \mathrm{~ms}$. Observed in the spectrum were emissions from the hydroxyl radical $(\cdot \mathrm{OH})$ between 306 and $309 \mathrm{~nm}$, nitrogen second positive system ( $\mathrm{N}_{2}$ SPS) between 296 and $380 \mathrm{~nm}$, nitrogen first negative system $\left(\mathrm{N}_{2}\right.$ FNS) between 390 and $440 \mathrm{~nm}$, excited helium between 470 and 707 $\mathrm{nm}$, and atomic oxygen (O) at $777 \mathrm{~nm} .{ }^{5}$ Emissions from the $\cdot \mathrm{OH}$ are known to occur due to the dissociation of water vapor molecules present in the feed He gas and ambient air (humidity $\sim 36 \%$ ) while the emissions from excited nitrogen species are due to the dissociation of nitrogen molecules present in ambient air. Emissions from He appeared through electron induced excitation of $\mathrm{He}$ from the feed gas and $\mathrm{O}$ was formed through the dissociation of oxygen or water vapor molecules. The $\cdot \mathrm{OH}$ observed in the spectrum formed $\mathrm{H}_{2} \mathrm{O}_{2}$ due to recombination reactions from the $\mathrm{OH}$ molecules. ${ }^{5} \mathrm{H}_{2} \mathrm{O}_{2}$ subsequently reacted with TAED and AA, resulting in the formation of PAA as depicted in Fig. 1.

\section{B. Measurement of $\mathrm{H}_{2} \mathrm{O}_{2}$ Concentration}

Measurement of $\mathrm{H}_{2} \mathrm{O}_{2}$ concentrations in PAW, plasma-activated AA (PAAA) and plasma-activated TAED (PAT) were carried out using the protocol described earlier. The calibration curve used to calculate the $\mathrm{H}_{2} \mathrm{O}_{2}$ concentration is shown in Fig. A1. The corresponding concentrations of $\mathrm{H}_{2} \mathrm{O}_{2}$ measured for PAW, PAAA, and PAT after 20 min of plasma treatment are shown in Fig. 4. The $\mathrm{H}_{2} \mathrm{O}_{2}$ concentration was the highest in PAT $(10 \mathrm{mM})$, followed by PAA $(6.5 \mathrm{mM})$ and then PAW $(2.5 \mathrm{mM})$. The higher concentration of $\mathrm{H}_{2} \mathrm{O}_{2}$ in PAT and PAAA compared to PAW was due to the dissociation of PAA into $\mathrm{H}_{2} \mathrm{O}_{2}$, which is explained in the next section.

\section{He Plasma Jet Generation of PAA from the Activation of TAED and AA}

$\mathrm{H}_{2} \mathrm{O}_{2}$ produced by the He plasma jet can react with TAED or AA, resulting in the formation of PAA. This takes place as follows: ${ }^{18}$

$$
\begin{gathered}
\text { TAED }+\mathrm{H}_{2} \mathrm{O}_{2} \rightarrow \text { DAED }+2 \text { PAA } \\
\text { PAA }+\mathrm{H}_{2} \mathrm{O}_{2} \rightleftharpoons \mathrm{AA}+\mathrm{H}_{2} \mathrm{O}_{2}
\end{gathered}
$$

The intermediate product DAED in Eq. (5) is called diacetylethylenediamine.

PAA formed in Reaction (5) through the reaction of TAED with $\mathrm{H}_{2} \mathrm{O}_{2}$ remains in equilibrium with its decomposition product, acetic acid, and 1 molecule of $\mathrm{H}_{2} \mathrm{O}_{2}$ 


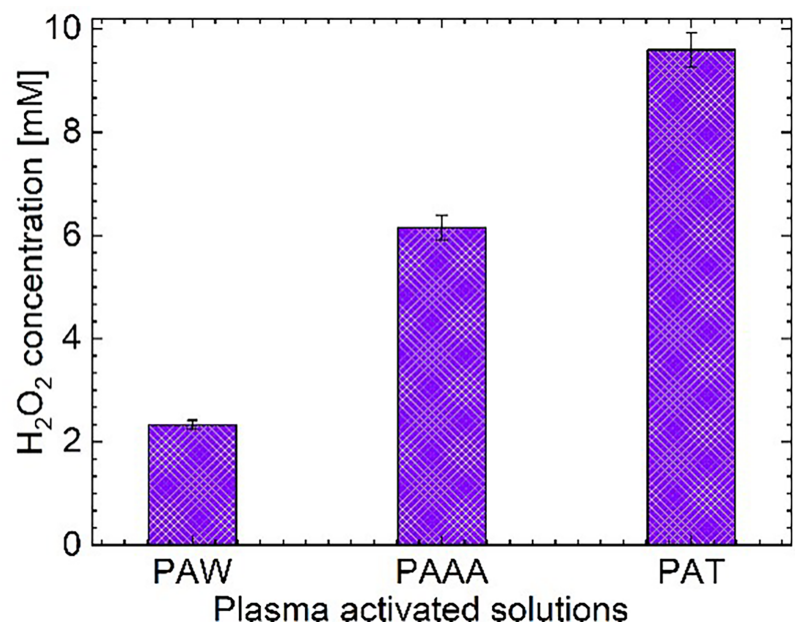

FIG. 4: $\mathrm{H}_{2} \mathrm{O}_{2}$ concentrations measured in PAW, PAAA, and PAT after 20 min He plasma jet treatment

[Reaction (6)]. The reversible reaction in (6) shows that $\mathrm{H}_{2} \mathrm{O}_{2}$ can also react with AA to form PAA. To measure the resultant concentrations of PAA in the plasma-treated solutions, we monitored the ability of PAA to oxidize KI. Catalase was added to the KI solution to neutralize $\mathrm{H}_{2} \mathrm{O}_{2}$, which ensured that the majority of $\mathrm{KI}$ oxidation was due to PAA and not $\mathrm{H}_{2} \mathrm{O}_{2}$ or other RONS produced by the He plasma jet. ${ }^{17}$ We had previously determined that this method could be used to selectively distinguish the PAAinduced oxidation of KI from other plasma-generated RONS. ${ }^{17}$ The concentration of PAA measured in the PAT and PAAA is presented in Fig. 5. The results show that PAT contained approximately two times higher concentration of PAA than PAAA. PAA was

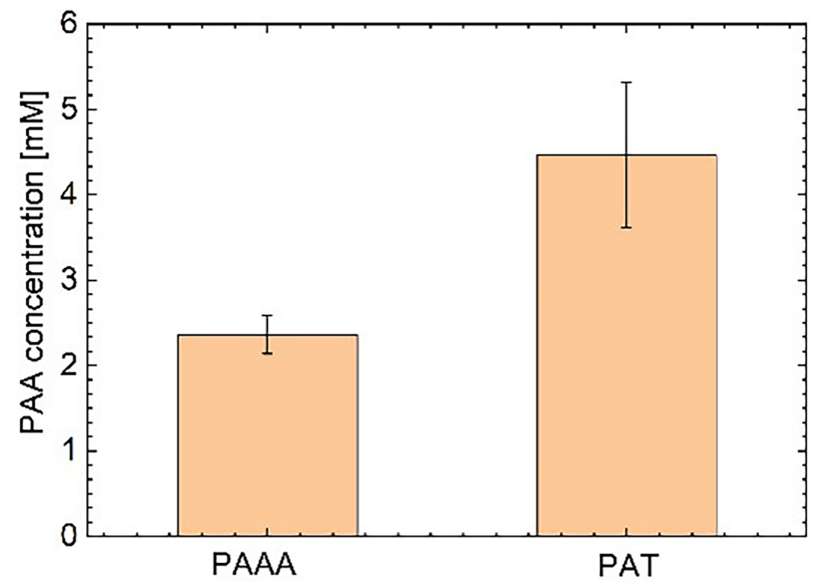

FIG. 5: Concentration of PAA measured for PAAA and PAT after 20 min He plasma jet treatment 
not detected in PAW alone as this solution did not contain acetyl donor molecules. ${ }^{17}$ The higher concentration of PAA detected in PAT compared to PAAA was due to the multiple acetyl groups in TAED compared to only one group in AA, resulting in double the number of PAA molecules generated per reaction with $\mathrm{H}_{2} \mathrm{O}_{2}$.

This explanation was confirmed by following the oxidation of KI by TAED and AA that was activated with different concentrations of $\mathrm{H}_{2} \mathrm{O}_{2}$. The results are shown in Fig. 6. Oxidation of KI was similar between the activated TAED and AA at $\mathrm{H}_{2} \mathrm{O}_{2}$ concentrations $\leq 5 \mathrm{mM}$. But at concentrations of $10-100 \mathrm{mM}$, activated TAED produced a higher level of KI oxidation compared to activated AA, and this difference increased as a function of $\mathrm{H}_{2} \mathrm{O}_{2}$ concentration. These results can be explained by the higher number of acetyl groups in TAED compared to AA as shown in Fig. 1. At lower $\mathrm{H}_{2} \mathrm{O}_{2}$ concentrations, there were not enough $\mathrm{H}_{2} \mathrm{O}_{2}$ molecules available to activate all of TAED's acetyl groups , resulting in a level of KI oxidation from PAA similar to that produced by the activated TAED and AA. Whereas at concentrations $>10 \mathrm{mM}$, the number of available of $\mathrm{H}_{2} \mathrm{O}_{2}$ molecules to activate the extra acetyl groups of TAED (compared to AA) increased, facilitating the production of more PAA molecules that could react with KI.

Because $\mathrm{H}_{2} \mathrm{O}_{2}$ is neutralized by catalase, an antioxidant released by bacteria as a protective measure against excessive oxidative stress (described in the Introduction), it is possible that PAA in PAAA and PAT can help overcome this form of AMR. To test this, the capacity of PAW, PAAA, and PAT to oxidize KI was tested with and without catalase. Figure 7 shows that the oxidative capacity of PAT is greater than that of PAAA which is greater than that of PAW. In the presence of $100 \mathrm{mg} / \mathrm{mL}$ catalase, which can completely neutralize up to $100 \mathrm{mM}$ of the $\mathrm{H}_{2} \mathrm{O}_{2}$ tested in this study (much more than the maximum $\mathrm{H}_{2} \mathrm{O}_{2}$ concentration of $\sim 10 \mathrm{mM}$ produced in the solutions in this study; see Fig. A3 in Appendix A), it is seen that the oxidative capacity of PAW is nearly eliminated. This result is attributed to the major oxidant in PAW (i.e., $\mathrm{H}_{2} \mathrm{O}_{2}$ ) being neutralized by catalase. Even with catalase, however, PAAA is still slightly oxidative. And PAT,

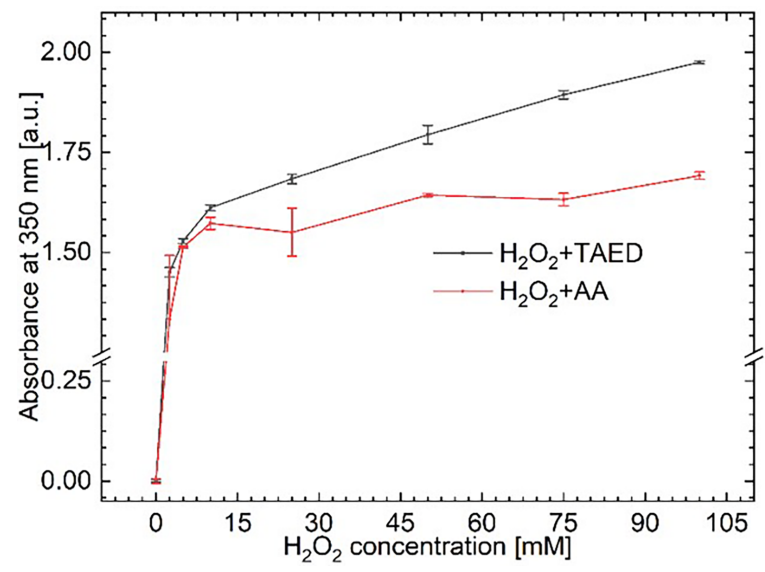

FIG. 6: Oxidation of KI by TAED and AA activated with different concentrations of $\mathrm{H}_{2} \mathrm{O}_{2}$ 


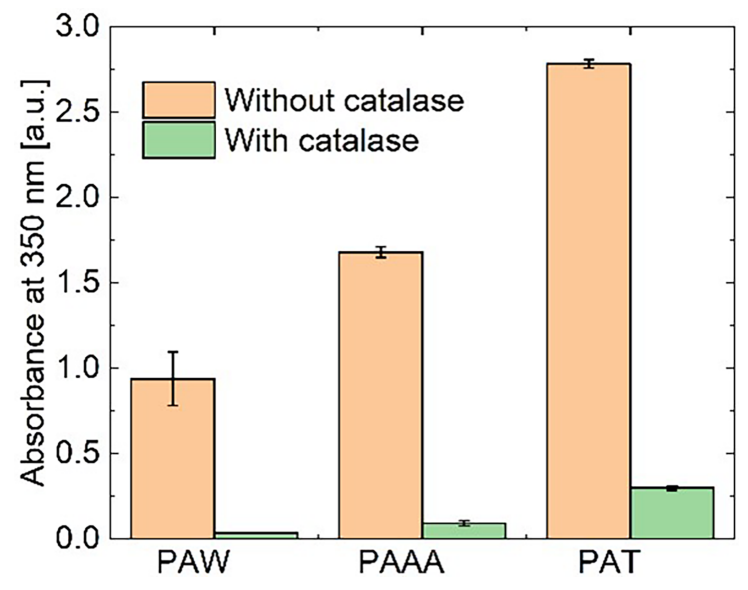

FIG. 7: Oxidation of KI by PAW, PAAA, and PAT with and without catalase

with the highest concentration of PAA, is the most efficient at oxidizing $\mathrm{KI}$ in the presence of catalase. Therefore, these results show that PAA indeed helps overcome a major antioxidant defense mechanism in bacteria, and consequently potentially helps resist against AMR.

\section{Antibacterial Assessment}

The antibacterial property of the PAW, PAAA, and PAT solutions was tested by their ability to reduce growth of the common wound pathogenic bacteria $P$. aeruginosa and $S$. aureus. Bacterial growth was assessed by measuring the turbidity of the bacterial broth at $\mathrm{OD}_{600}$, where a higher $\mathrm{OD}_{600}$ correlates with increased turbidity and consequently more bacteria. The results are presented in Fig. 8. Compared to untreated bacteria, PAW effectively reduced the growth of $P$. aeruginosa and to a lesser degree $S$. aureus. PAAA was more effective than PAW at reducing the growth of both bacteria but still could not completely inhibit the growth of $S$. aureus, presumably due its different Gram-positive membrane providing a greater barrier to the penetration of oxidative molecules compared to the Gram-negative membrane of $P$. aeruginosa. PAT proved the most effective antibacterial agent in this study, achieving complete inhibition of bacterial growth. Therefore, the bacterial assay showed that the number of available acetyl groups from the antimicrobial precursor agent is an important parameter in enhancing the antibacterial efficacy of the plasma-activated solution because it influences the soultion's capacity to produce PAA.

\section{CONCLUSIONS}

This paper investigated the formation of peracetic acid (PAA) from the plasma-activated acetyl group-containing molecules tetraacetylethylenediamine (TAED) and acetic acid 


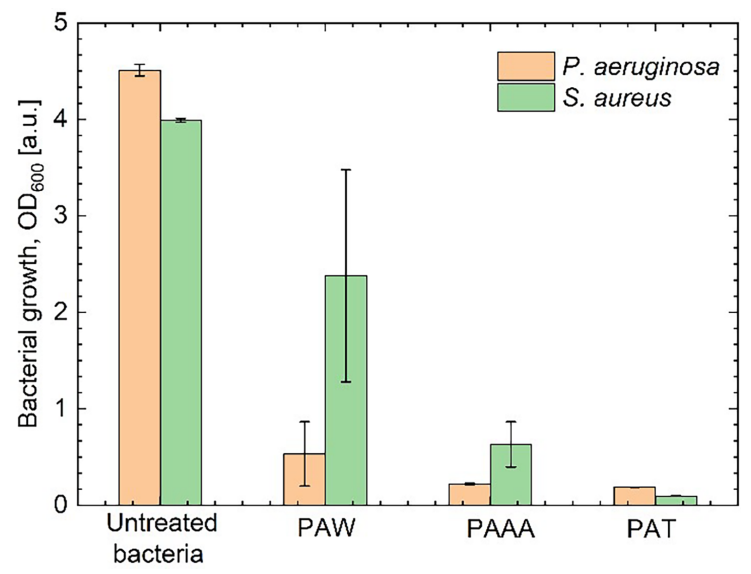

FIG. 8: Antibacterial assessment of PAW, PAAA, and PAT compared to untreated bacteria (positive control of bacterial growth)

(AA) for antimicrobial applications. TAED and AA were activated by a helium plasma jet, and the antimicrobial efficacy of the respective solutions was compared to their hydrogen peroxide $\left(\mathrm{H}_{2} \mathrm{O}_{2}\right)$ and PAA concentrations and their ability to oxidize a potassium iodide solution. Plasma-activated TAED produced a higher concentration of $\mathrm{H}_{2} \mathrm{O}_{2}$ and PAA compared to plasma-activated AA, resulting in a greater oxidative capacity of potassium iodide. This correlated with the more potent oxidant plasma-activated TAED exhibiting higher efficacy in killing the common wound pathogens Pseudomonas aeruginosa and Staphylococcus aureus. The superior antimicrobial efficacy of plasmaactivated TAED compared to plasma-activated AA is attributed to TAED having more acetyl groups, which react with $\mathrm{H}_{2} \mathrm{O}_{2}$ to produce a higher concentration of PAA. Our results suggest that TAED is a better option than AA for antimicrobial applications when coupled with plasma treatments.

\section{ACKNOWLEDGMENTS}

The authors would like to thank the EPSRC (Grant Nos. EP/R003556/1 and EP/ V00607X/1). E.J.S. acknowledges the Australian Research Council Future (Fellowship No. FT190100263), the National Health Medical Research Council Ideas (Grant No. 2002510), and the Future Industries Accelerator Mobility Scheme MOB024.

\section{REFERENCES}

1. Ikawa S, Tani A, Nakashima Y, Kitano K. Physicochemical properties of bactericidal plasma-treated water. J Phys D: Appl Physics. 2016;49:1-9.

2. Kaushik NK, Ghimire B, Li Y, Adhikari M, Veerana M, Kaushik N, Jha N, Adhikari B, Lee SJ, Masur K, Woedtke TV, Weltmann KD, Choi EH. Biological and medical applications of plasma activated water, media and solutions. Biol Chem. 2018;400:39-62. 
3. Herianto S, Hou CY, Lin CM, Chen HL. Nonthermal plasma-activated water: A comprehensive review of this new tool for enhanced food safety and quality. Compr Rev Food Sci Food Saf. 2021;20: 583-626.

4. Lamichhane P, Ghimire B, Mumtaz S, Paneru R, Ki SH, Choi EH. Control of hydrogen peroxide production in plasma activated water by utilizing nitrification. J Phys D: Appl Phys. 2019;52:1-9.

5. Ghimire B, Szili EJ, Patenall BL, Lamichhane P, Gaur N, Robson AJ, Trivedi D, Thet NT, Jenkins ATA, Choi EH, Short RD. Enhancement of hydrogen peroxide production from an atmospheric pressure argon plasma jet and implications to the antibacterial activity of plasma activated water. Plasma Source Sci Technol. 2021;30:1-15.

6. Oh J, Szili E, Hatta A, Ito M, Shirafuji T. Tailoring the chemistry of plasma-activated water using a DC-pulse-driven non-thermal atmospheric-pressure helium plasma jet. Plasma. 2019;2:127-37.

7. Reuter S, Tresp H, Wende K, Hammer MU, Winter J, Masur K, Schmidt-Bleker A, Weltmann KD. From RONS to ROS: Tailoring plasma jet treatment of skin cells. IEEE Trans Plasma Sci. 2012;40:2986-93.

8. Heinlin J, Isbary G, Stolz W, Morfill G, Landthaler M, Shimizu T, Steffes B, Nosenko T, Zimmermann JL, Karrer S. Plasma applications in medicine with a special focus on dermatology. J Eur Acad Dermatol Venereol. 2011;25:1-11.

9. Barjasteh A, Dehghani Z, Lamichhane P, Kaushik N, Choi EH, Kaushik NK. Recent progress in applications of non-thermal plasma for water purification, bio-sterilization, and decontamination. Appl Sci. 2021;11:1-22.

10. Lamichhane P, Veerana M, Lim JS, Mumtaz S, Shrestha B, Kaushik NK, Park G, Choi EH. Lowtemperature plasma-assisted nitrogen fixation for corn plant growth and development. Int J Mol Sci. 2021;22:1-22.

11. Attri P, Ishikawa K, Okumura T, Koga K, Shiratani M. Plasma agriculture from laboratory to farm: A review. Processes (MDPI). 2020;8:1-22.

12. Mai-Prochnow A, Clauson M, Hong J, Murphy AB. Gram positive and Gram negative bacteria differ in their sensitivity to cold plasma. Sci Rep. 2016;6:1-12.

13. Jablonowski H, Hänsch MACh, Dünnbier M, Wende K, Hammer MU, Weltmann K-D, Reuter S, Woedtke TV. Plasma Jet's shielding gas impact on bacterial inactivation. Biointerphases. 2015; 10:1-9.

14. Isbary G, Morfill G, Schmidt HU, Georgi M, Ramrath K, Heinlin J, Karrer S, Landthaler M, Shimizu T, Steffes B, Bunk W, Monetti R, Zimmermann JL, Pompl R, Stolz W. A first prospective randomized controlled trial to decrease bacterial load using cold atmospheric argon plasma on chronic wounds in patients. Brit J Dermatol. 201;163:78-82.

15. Zimmermann JL, Shimizu T, Schmidt HU, Li YF, Morfill GE, Isbary G. Test for bacterial resistance build-up against plasma treatment. New J Phys. 2012;14:1-17.

16. Hathaway HJ, Patenall BL, Thet NT, Sedgwick AC, Williams GT, Jenkins ATA, Allinson SL, Short RD. Delivery and quantification of hydrogen peroxide generated via cold atmospheric pressure plasma through biological material. J Phys D: Appl Phy. 2019;52:1-8.

17. Szili EJ, Ghimire B, Patenall BL, Rohaim M, Mistry D, Fellows A, Muhammad M, Jenkins ATA, Short RD. On-demand cold plasma activation of acetyl donors for bacteria and virus decontamination. Appl Phys Lett. 2021;119:1-5.

18. Sofokleous P, Ali S, Wilson P, Buanz A, Gaisford S, Mistry D, Fellows A, Day RM. Sustained antimicrobial activity and reduced toxicity of oxidative biocides through biodegradable microparticles. Acta Biomater. 2017;64:301-12.

19. Ghimire B, Sornsakdanuphap J, Hong YJ, Uhm HS, Weltmann KD, Choi EH. The effect of the gap distance between an atmospheric-pressure plasma jet nozzle and liquid surface on $\mathrm{OH}$ and N2 species concentrations. Phys Plasmas. 2017;24:1-12.

20. Ghimire B, Szili EJ, Lamichhane P, Short RD, Lim JS, Attri P, Masur K, Weltmann KD, Hong SH, Choi EH. The role of UV photolysis and molecular transport in the generation of reactive species in a tissue model with a cold atmospheric pressure plasma jet. Appl Phys Lett. 2019;114:1-5.

Volume 11, Issue 4, 2021 


\section{APPENDIX A.}

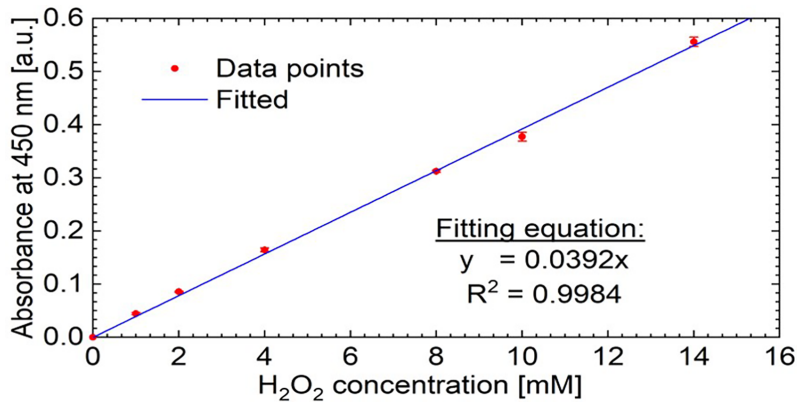

FIG. A1: Calibration curve to deduce concentration of $\mathrm{H}_{2} \mathrm{O}_{2}$ in PAW, PAAA, and PAT

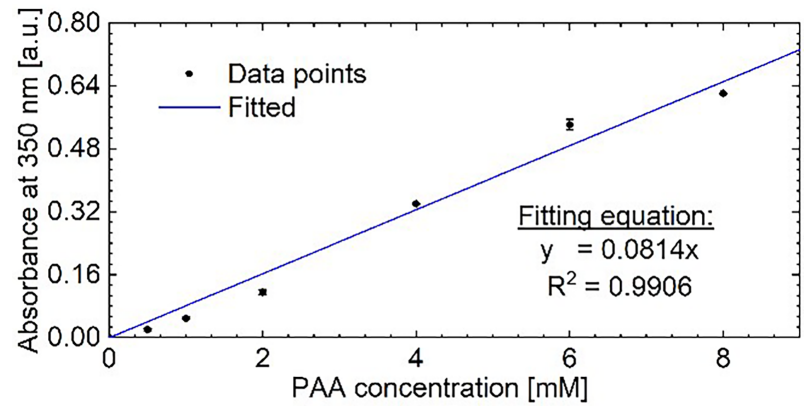

FIG. A2: Calibration curve to deduce concentration of PAA in PAAA and PAT

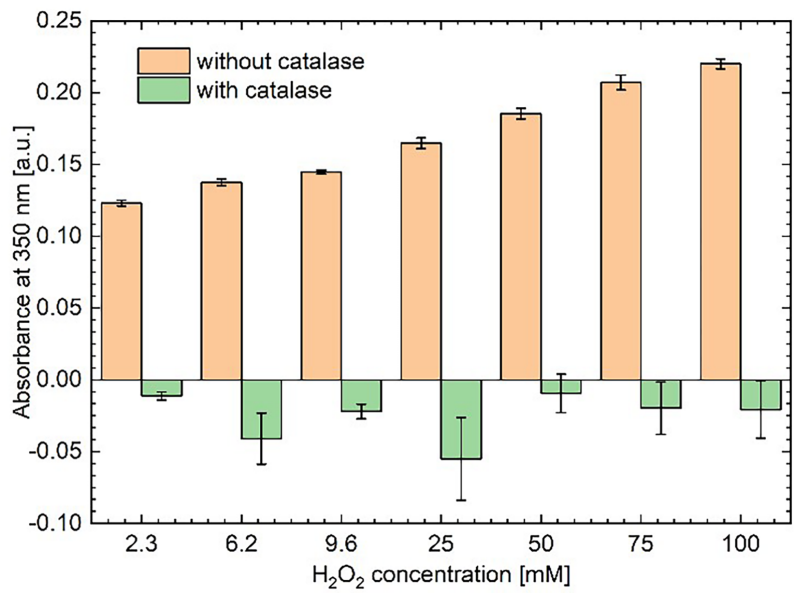

FIG. A3: Quenching of different concentrations of $\mathrm{H}_{2} \mathrm{O}_{2}$ by catalase 